\title{
Vertical structure and diabatic processes of the Madden-Julian oscillation
}

Book or Report Section

Accepted Version

Klingaman, N. P., Jiang, X., Xavier, P. K., Petch, J., Waliser, D. and Woolnough, S. J. (2017) Vertical structure and diabatic processes of the Madden-Julian oscillation. In: Chang, C.-P., Kuo, H.-C., Lau, N.-C., Johnson, R. H., Wang, B. and Wheeler, M. C. (eds.) Global Monsoon System: Research and Forecast (3rd Edition). World Scientific Series on Asia-Pacific Weather and Climate, 9. World Scientific, New Jersey, pp. 161-172. ISBN 9789813200906 doi: https://doi.org/10.1142/10305 Available at https://centaur.reading.ac.uk/69153/

It is advisable to refer to the publisher's version if you intend to cite from the work. See Guidance on citing.

To link to this article DOI: http://dx.doi.org/10.1142/10305

Publisher: World Scientific

All outputs in CentAUR are protected by Intellectual Property Rights law, including copyright law. Copyright and IPR is retained by the creators or other copyright holders. Terms and conditions for use of this material are defined in the End User Agreement. 


\section{CentAUR}

Central Archive at the University of Reading

Reading's research outputs online 


\title{
Chapter 13
}

\section{Vertical Structure and Diabatic Processes of the Madden-Julian Oscillation}

\author{
Nicholas P. Klingaman*, Xianan Jiang, Prince K. Xavier, \\ Jon Petch, Duane Waliser, Steven J. Woolnough \\ National Centre for Atmospheric Science-Climate, \\ University of Reading, Reading, Berkshire, RG6 6BB, United Kingdom \\ ${ }^{*}$ n.p.klingaman@reading.ac.uk \\ http://yotc.ucar.edu/mjo/vertical-structure-and-diabatic-processes-mjo
}

\begin{abstract}
The "Vertical Structure of Diabatic Processes of the Madden-Julian Oscillation" global-model evaluation project developed a novel experimental framework, which produces a complete characterization of models' abilities to simulate the Madden-Julian oscillation (MJO). The three components of the project comprise 2-day and 20-day hindcasts and 20-year simulations; each obtained heating, moistening and momentum tendencies from the models' sub-grid parameterizations. Thirty-five centers provided output for at least one component; nine centers provided data for all three. The models vary greatly in MJO fidelity in climate and hindcast experiments, yet fidelity in one was not correlated with fidelity in the other. In 20-year simulations, strong MJO models demonstrated heating, vertical-velocity and zonal-wind profiles that tilted westward with height, as in reanalysis data. The 20-day hindcasts showed no correspondence between the shape of the heating profile and hindcast skill. Low-to-mid-level moistening at moderate rain rates was a consistent feature of highskill models and absent from low-skill models, suggesting a role for boundary-layer and congestus clouds in the MJO transition, which was confirmed by timestep data from the 2-day hindcasts. These hindcasts revealed a poor simulation of the MJO transition phase, even at short leads, with large mid-tropospheric dry biases and discrepancies in radiative-heating profiles.
\end{abstract}

\section{Introduction}

The Madden-Julian Oscillation (MJO; Madden and Julian, 1971) is the leading mode of subseasonal (30-70 day) tropical variability. The active (suppressed) phase of the MJO consists of a large-scale envelope of deep (suppressed) convection closely followed by strong (weak) lowlevel westerly winds (Lawrence and Webster, 2002). MJO events often form in the equatorial Indian Ocean, before propagating east through the Maritime Continent into the West Pacific at approximately a $5 \mathrm{~ms}^{-1}$ (Madden and Julian, 1994). As the MJO circumnavigates the tropics, it modulates regional precipitation and the large-scale circulation, including the Australian
(Wheeler et al., 2009), African (Lavender and Matthews, 2009), South Asian (Pai et al., 2011) and North American (Lorenz and Hartmann, 2006) monsoons. Such modulations also affect tropical cyclogenesis in the Indian, Pacific and Atlantic basins (Camargo et al., 2009). The circulation response to the MJO-associated diabatic heating extends to the extra-tropics, producing a teleconnection to the North Atlantic Oscillation (Cassou, 2008). Therefore, the MJO provides a significant source of sub-seasonal predictability globally.

Although many studies have documented the impacts of the MJO, the fundamental physics of its generation, maintenance and propagation are intensely debated. Proposed theories focus 
on instabilities arising from interactions between components of the diabatic heating and the large-scale circulation. These theories emphasize different sources of heating that drive moisture convergence at different heights, including freetropospheric moisture convergence from lowlevel heating (Lau and Peng, 1987), frictional moisture convergence in the boundary layer (Wang and Rui, 1990), as well as radiative cooling that drives instability and tropospheric moisture convergence (Stephens et al., 2004). In modelling studies, Li et al. (2009) highlighted low-level heating from shallow convection prior to the onset of deep convection, while Fu and Wang (2009) found that stratiform, mid-level heating was essential. This uncertainty is further complicated by disagreement in profile shape and amplitude among observations and reanalysis, including among products processed from the same Tropical Rainfall Measuring Mission (TRMM) instruments (Ling and Zhang, 2011; Jiang et al., 2011). Moistening from detraining convection likely also plays a role in sustaining the suppressed phase of the MJO. Woolnough et al. (2010) found that models which produced more precipitation and net drying below the freezing level in the suppressed phase were unable to adequately transition to the active phase. As a result of this lack of physical understanding, most general circulation models (GCMs) exhibit biases in diabatic heating and moistening processes, as well as incorrect or weak feedbacks between that heating and the large-scale circulation. These biases may lead to the substantial errors found in GCM representations of the MJO (e.g., Kim et al., 2009), which in turn limit sub-seasonal skill.

\section{The "Vertical Structure and Diabatic Processes" of the MJO Global-Model Evaluation Project}

We are conducting a novel global-model evaluation project to assess the vertical structure and diabatic processes of the MJO in GCMs. The project is endorsed by the Global Atmospheric Systems Studies (GASS) panel, the Years of Tropical Convection (YoTC) and the World Climate Research Programme-World Weather Research Programme (WCRP-WWRP) MJO Task Force. The project has developed a framework through which model developers can improve their sub-gridscale physical parameterisations, by linking errors in the simulation of the MJO to errors in GCM vertical profiles of heat, moisture and momentum. The MJO provides a rigorous test for GCM physics schemes, as well as the interactions between the physics and the large-scale dynamics. Due to the many teleconnections from the MJO, reducing model MJO biases should also improve the simulation of other tropical and extra-tropical phenomena. A key advantage of this evaluation project is the acquisition of temperature, moisture and momentum tendencies from each of the model sub-grid physics schemes; these data are not available from previous, more general intercomparisons, such as the Coupled Model Intercomparison Project (CMIP), particularly not at the temporal frequency obtained here.

The three project components are designed to take advantage of known links between biases in short-range (e.g., NWP) forecasts and climate simulations (Boyle et al., 2008):

Component 1: Twenty-year climate simulations with either atmosphere-only or coupled GCMs. These simulations assess the overall fidelity of each model's representation of the MJO, relative to the climatology and mean-state biases of that model, as well as teleconnections from the MJO to monsoon systems and extra-tropical variability. Six-hourly output of all sub-grid tendencies has been obtained for the full twentyyear period.

Component 2: Two-day hindcasts, initialized daily during the active phases of two strong MJO events (20 October-10 November 2009 and 20 December-10 January 2010) in the Indian 
Ocean within the YoTC period (Cases E and F), initialized from the European Centre for Medium-range Weather Forecasts (ECMWF) YoTC analyses. Tendencies are obtained every timestep on GCM horizontal and vertical grids, over the Warm Pool region. This enables detailed, comprehensive comparisons of parameterizations when models are close to the initial state and contain an active MJO.

Component 3: Twenty-day hindcasts, initialized daily during the two events above, but for a wider range of start dates to capture the MJO genesis and lysis at lead times beyond ten days. Three-hourly output is used to diagnose changes in GCM behavior and skill with lead time, as GCMs move from the near-observed state identified in component 2 - towards their preferred climate - identified in component 1 . The aim is to link the degradation in a model's representation of the MJO with forecast lead time to the growth of biases in diabatic heating and moistening profiles.

Thirty-five centers provided data for at least one component; nine provided data for all three components. A complete list of participating centers, which experiments each centre performed and details of the model configurations are available from our project website: http://yotc.ucar.edu/mjo/vertical-structureand-diabatic-processes-mjo. All data collected are available to the community through a link on the above page.

\section{Component 1: Twenty-Year Climate Simulations}

Model fidelity in representing the eastward propagation of the MJO in 26 GCM simulations is assessed by lag-regression and wavenumberfrequency analysis. In Fig. 1, Hovmöller diagrams of rainfall evolution based on observed and GCM-simulated rainfall are derived by lag-regression of 20-100-day band-pass filtered anomalous rainfall against itself averaged over an Indian Ocean box. The observed systematic eastward propagation of the MJO is captured in only about one-quarter of models. Based on pattern correlations of Hovmöller diagrams between each model simulation and TRMM, two groups of seven GCMs are identified as the top (red labels) and bottom (blue labels) 25\% GCMs for representing the MJO. Similar skill scores can be derived by applying the "east/west variance ratio" approach based on wavenumber- frequency analysis (Kim et al., 2009).

Various process-oriented metrics [e.g., those suggested by the MJO Task Force (CLIVAR Madden-Julian Oscillation Working Group, 2009)] have been examined to identify key processes essential for faithful MJO representation. These include rainfall fraction from large-scale condensation, the rainfall probability density function $(\mathrm{PDF})$, vertical relative humidity $(\mathrm{RH})$ profiles as a function of rain rate and the 850 hPa mean zonal wind over the equatorial eastern Indian Ocean and western Pacific. Analyses suggest that the processes responsible for reliable MJO simulations in the top $25 \%$ GCMs are complex; no single process yet examined is strongly linked to the improved MJO in these models. For example, of five selected top $25 \%$ GCMs, the total rainfall in two is dominated by the convective component, while the convective and large-scale components play comparable roles in the other three. We note that air-sea coupling improves the MJO in several models, particularly the CNRM GCM, as previously reported (e.g., Inness and Slingo, 2003).

To further elucidate key processes for realistic MJO simulation, the vertical structures of anomalous zonal wind, temperature, vertical velocity, diabatic heating, and specific humidity corresponding to intra-seasonal rainfall variability over the Indian Ocean are analyzed for the top and bottom $25 \%$ of GCMs; the results are compared to ERA-Interim (Fig. 2). TAMUmodCAM4 was excluded from the top $25 \%$ composite, since that GCM prescribes an observed diabatic-heating profile based on MJO phase; 

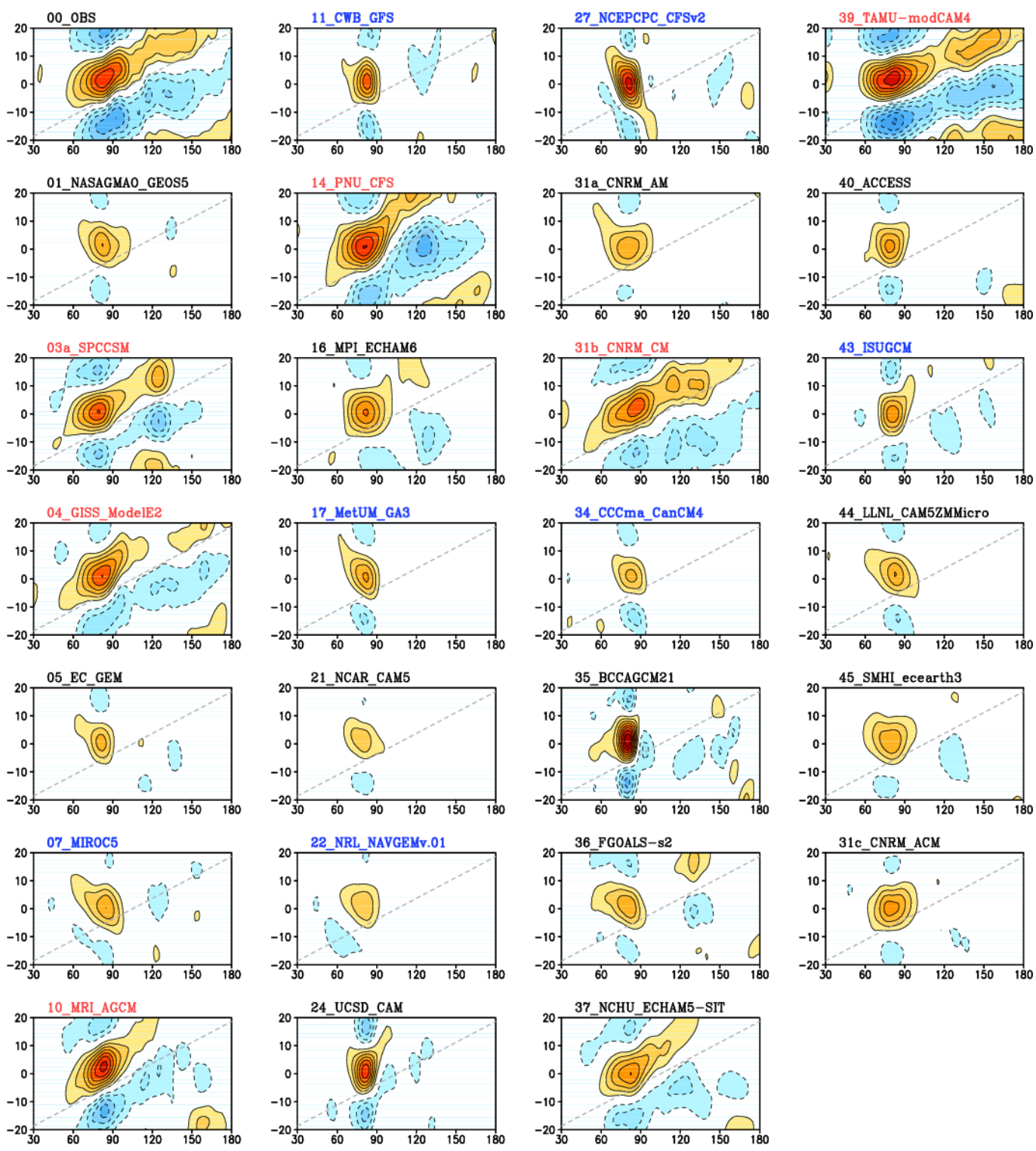

$\begin{array}{llllllllllllllllll}-2 & -1.75 & -1.5 & -1.25 & -1 & -0.75 & -0.5 & -0.25 & 0.25 & 0.5 & 0.75 & 1 & 1.25 & 1.5 & 1.75 & 2\end{array}$

Fig. 1. Longitude $\left({ }^{\circ} \mathrm{E}\right)$-time (day) diagrams of latitude-averaged $\left(10^{\circ} \mathrm{S}-10^{\circ} \mathrm{N}\right)$ rainfall regressed on area-averaged $\left(75-85^{\circ} \mathrm{E}, 5^{\circ} \mathrm{S}-5^{\circ} \mathrm{N}\right)$ rainfall. Rainfall was first $20-100$ day bandpass-filtered. Regressions are scaled by the standard deviation of area-averaged rainfall; units are $\mathrm{mm}_{\text {day }}{ }^{-1}$. The dashed line is $5 \mathrm{~m} \mathrm{~s}^{-1}$ eastward propagation. The top $25 \%$ (red) and bottom 25\% (blue) GCMs are identified by pattern correlation with TRMM (OBS; top left).

this made very small differences to the composites. The most prominent observed features in the vertical profiles of these fields are wellcaptured in the top $25 \%$ composite. In contrast, deficiencies are seen in the profiles from the bottom $25 \%$ GCMs: the first baroclinic responses in zonal wind associated with enhanced convection are not well-defined; and the westward tilt with 

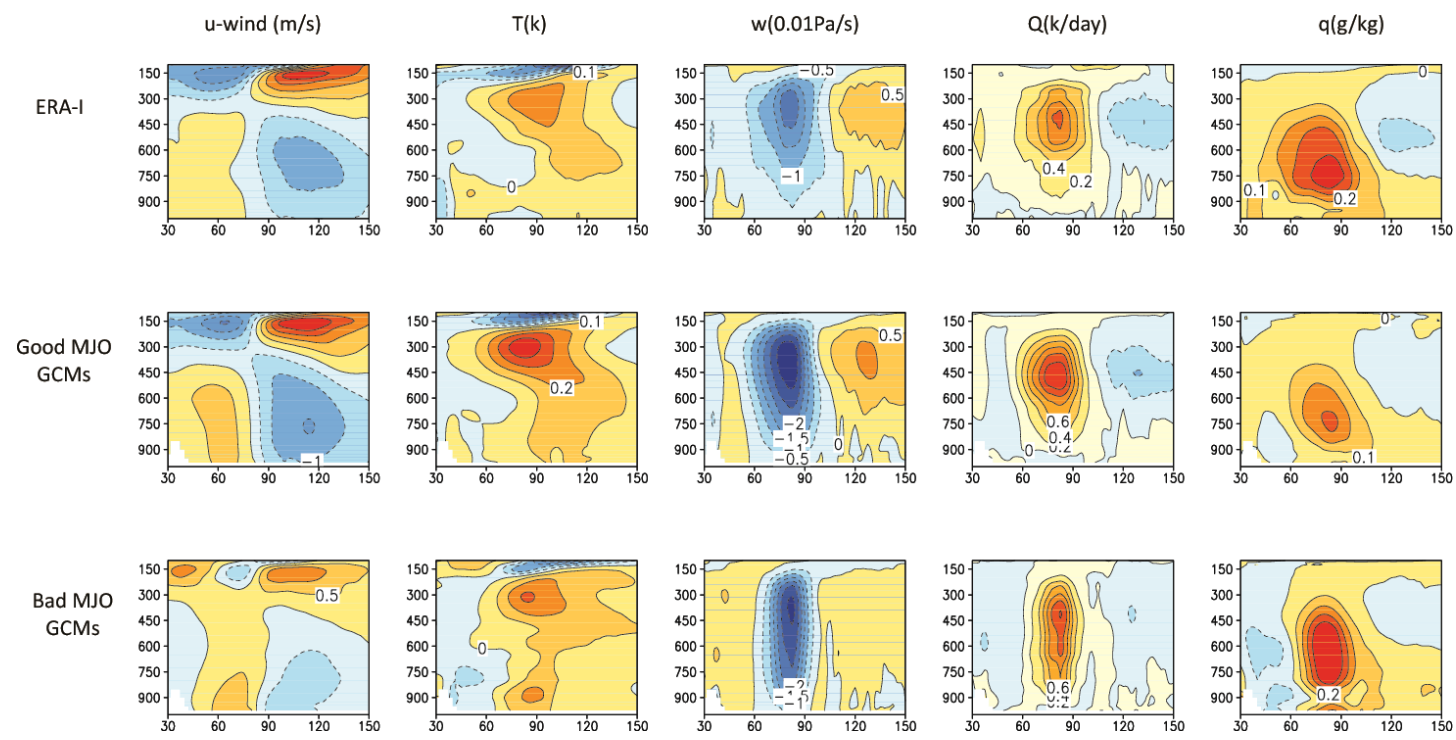

Fig. 2. Pressure $(\mathrm{hPa})$-longitude $\left({ }^{\circ} \mathrm{E}\right)$ profiles of lag-regressed zonal wind, temperature, vertical velocity, diabatic heating, and specific humidity onto 20-100-day bandpass-filtered, area-averaged Indian Ocean rainfall $\left(75-85^{\circ} \mathrm{E}\right.$; $5^{\circ} \mathrm{S}-5^{\circ} \mathrm{N}$ ) based on ERA-Interim (top) and the composites of the top $25 \%$ GCMs (red labels in Fig. 1, excluding TAMU-modCAM4) and the bottom $25 \%$ GCMs (blue labels in Fig. 1). All variables are averaged $10^{\circ} \mathrm{S}-10^{\circ} \mathrm{N}$.

height in vertical velocity, diabatic heating, and moisture fields seen in reanalysis and the top $25 \%$ GCMs is not clearly evident. This may indicate a lack of key pre-conditioning processes for the eastward-propagating MJO.

More detailed analyses have been carried out to understand the essential differences in the vertical structures associated with intraseasonal rainfall variability between these two groups of GCMs as shown in Fig. 2, including energetic conversion terms (Holloway et al., 2013), the moist static energy budget (Maloney, 2009; Andersen and Kuang 2012), and normalized gross moist stability (Raymond et al., 2009; Benedict et al., 2014). These will be reported separately.

\section{Component 2: Short-Range Hindcasts}

In the 48-hour hindcasts, $12-36$ hours is used as the time window for analysis that minimizes model spin-up effects and differences in
Case 1 Precip. (12-36 hrs, 75-80E, 0-5N)

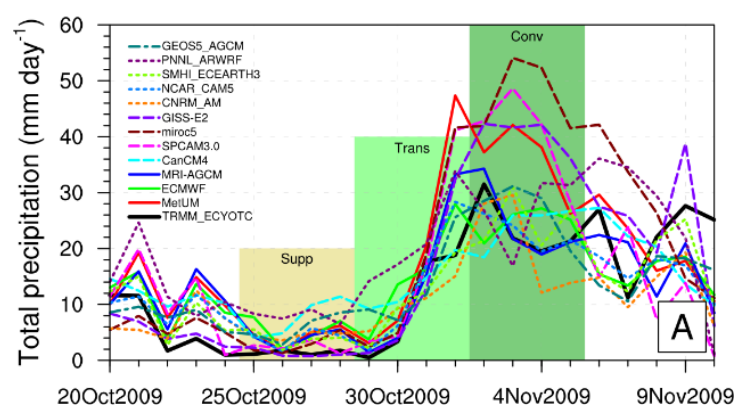

Fig. 3. Time series of $12-36$ hours total precipitation from TRMM (solid black) and models over $75-80^{\circ} \mathrm{E}, 0^{\circ}$ $5^{\circ} \mathrm{N}$ for YoTC Case E ("Case 1"). Three phases of the convective transition are marked as suppressed, transition and convective depending on the rainfall amounts.

the evolution of the large-scale dynamics. We focus on understanding the transition of MJO convection over a sufficiently large sub-domain that can represent the large-scale convective transition. A $5^{\circ} \times 5^{\circ}$ domain is chosen $\left(75^{-}\right.$ $\left.80^{\circ} \mathrm{E}, 0^{\circ}-5^{\circ} \mathrm{N}\right)$ that is large enough to include information from the coarser resolution models (e.g., SPCAM3.0, CanCM4). Figure 3 shows 
time series of $12-36$ hour accumulated precipitation over the $5^{\circ} \times 5^{\circ}$ box above for MJO case 1 (YoTC Case E) from TRMM and models. Figure 3 shows the suppressed phase, initiation of MJO convection and its transition towards a strong convective regime. All models show some degree of skill in capturing these phase transitions, however there are large differences in precipitation amounts. All models produce too much rain in the low-rain regime, a known problem in GCMs (e.g. Stephens et al., 2010; Xavier, 2012). GISS-E2 and SP-CAM3.0 produce the lowest rain amounts in the suppressed phase, while MetUM, SPCAM3.0 and MIROC5 are the wettest models during the convective phase.

Models are initialized from ECMWF-YoTC analysis; biases represent adjustment of temperature and humidity in the GCMs. Figure 4 shows the difference between 12-36 hour average
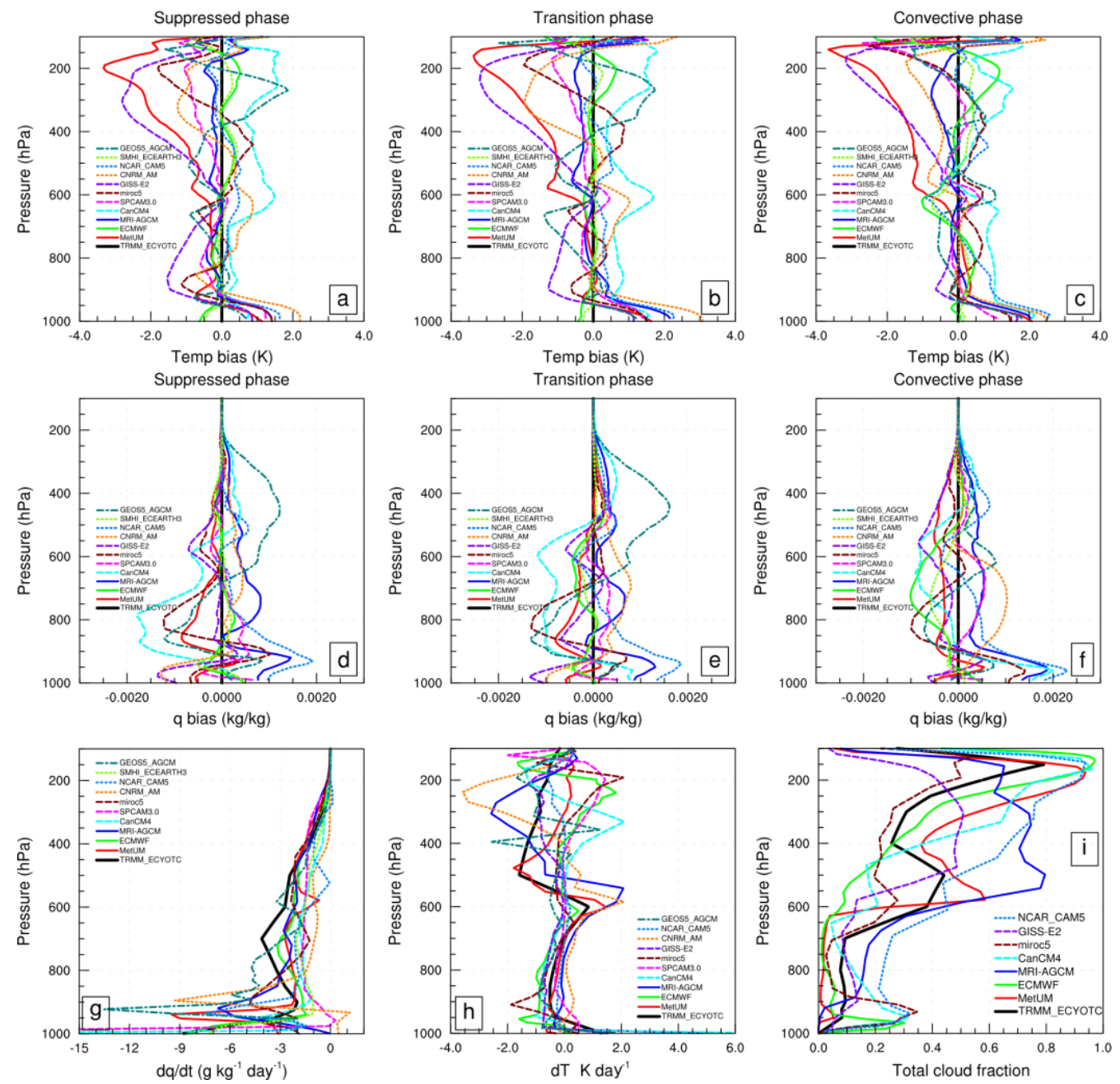

Fig. 4. Difference between $(\mathrm{a}-\mathrm{c})$ 12-36 hour average temperature and $(\mathrm{d}-\mathrm{f})$ specific humidity from the corresponding ECMWF YoTC 3-24-hour forecasts. Biases for suppressed (left panels), transition (middle) and convective phases (right panels) for YoTC Case E are shown (phases are defined in Fig. 3). (g) shows moisture tendencies due to convection during the transition phase; $(\mathrm{h})$ shows the temperature tendency due to the radiation scheme in the convective phase; (i) shows the the total cloud fraction during convective phase. 
temperature $(\mathrm{a}-\mathrm{c})$ and specific humidity $(\mathrm{q}, \mathrm{d}-\mathrm{f})$ from the corresponding ECMWF-YoTC 0-23hour forecasts for the three phases. Most models have warm biases near the surface in all three phases. Temperatures remain fairly close to the YoTC forecasts up to about the freezing level; a few models (e.g. MetUM, GISS-E2, CNRM AM) develop large cold biases above this which peak in the upper troposphere (Fig. 4ac). Humidity (q) biases are much more varied for models, although many models show midlevel dry biases in the suppressed and transition phases.

An important feature of the MJO suppressed-convective transition is gradual midlevel moistening due to shallow cumulus and cumulus congestus clouds. This moistening and associated latent heating play a role in preconditioning the atmosphere for intense convection (Benedict and Randall, 2007). Figure 4g shows the moisture tendencies from the convection scheme during the transition phase. The thick black line is the tendency from ECMWF YoTC 0-23-hour forecasts. The YoTC tendencies are strongly a function of ECMWF model parameterizations, despite better constrained dynamics than the models. We treat the YoTC tendencies as a broad guideline for evaluating diabatic processes. The models' moisture tendencies are shown in colors. The removal of moisture due to convection at mid-levels is often a signature of cumulus congestus. Models produce varying amounts of shallow convective drying, but with relatively low mid-level values, which may reduce moistening prior to deep convection.

Temperature biases in the models have larger spread above $600 \mathrm{hPa}$ compared to the lowermid levels. Temperature tendencies from physics and dynamics from the models (not shown) suggest that even though there are large differences among models in the tendency terms, there is general agreement on the sign of the tendencies, except for the radiation tendencies during the convective phase (Fig. 4h). Temperature tendencies due to radiation schemes show large (relative to their mean value) spread above $600 \mathrm{hPa}$. Some of these large uncertainties may be related to the representation of cloud properties in the models. Figure $4 \mathrm{i}$ shows the total cloud fraction during the convective phase of MJO. Above the freezing level, models tend to have large differences in their cloud fraction. For example, the ECMWF model produces $20 \%$ cloud fraction at around $500 \mathrm{hPa}$ while MRI-AGCM produces almost $80 \%$. There are large spreads in cloud-liquid and ice profiles (not shown), which may affect the upper-level heating differences and large-scale temperature biases. However, it remains a challenge to extract a precise relationship between radiative tendencies and MJO performance. There is no truth available to estimate the biases in radiative-heating and cloud profiles. A lack of clear and consistent clustering of models in temperature, radiative or cloud profiles at short range makes it difficult to relate to the MJO performance in the other components, given that the short-range results are based on a single MJO event and on a relatively smaller region.

Nevertheless this framework emphasizes the general behavior of model physics in terms of their uncertainties and interactions with large-scale dynamics. The inter-model spread in diabatic heating and moistening processes highlighted here calls for more accurate representation of shallow cumulus/congestus and cloud-radiative properties. More focused analysis is required to understand the relationship between heating, moistening and cloud properties at short-range and the key biases relevant for MJO simulation in NWP and climate models.

\section{Component 3: Long-Range Hindcasts}

In the 20-day hindcasts, model "skill" is evaluated by computing the Wheeler and Hendon (2004) Real-time Multi-variate MJO (RMM) 
indices from each model, using the method in Gottschalck et al. (2010), and comparing against observed RMM indices from satellitederived outgoing longwave radiation (OLR) and ECMWF YoTC analysis zonal winds. "Skill" is a loose term here, since only two events were simulated using a total of 94 start dates. This experiment aims not to provide a thorough assessment of skill, but rather to distinguish between the diabatic processes of those models that simulate these MJO cases well from those that do so poorly.

The 13 GCMs and two statistical models - linear inverse models, "LM" and "LS" in Fig. 5 - display a wide range of skill for these events (Fig. 5a). Several models, such as the two versions of the Community Atmospheric Model, version 5 (CAM5; "C5" and "CZ"), show greater than 20 days' skill at a bivariate correlation of 0.7 ; others are similar to or worse than a persistence forecast ("PE"), which implies that the MJO displays little or no propagation. All GCMs show greater skill for RMM2, which represents the anti-correlation in convection between the Indian Ocean and the West Pacific, than in RMM1, which represents variability over the Maritime Continent (Fig. 5b). For the 11 GCMs that also supplied results to Component 1 , the daily climatology of the 20-year simulations was used to determine how quickly the model drifted from the initial conditions towards its attractor, using fields such as winds and OLR in the deep tropics (not shown). Those models that drifted more (less) quickly displayed lower (higher) skill; lower-skill GCMs tend to damp sub-seasonal anomalies and return to their mean climates.

Several process-oriented diagnostics were applied, such as vertical profiles of specific humidity and vertical-velocity anomalies as functions of rainfall (e.g., Thayer-Calder and Randall, 2009). There were no significant correlations between fidelity in these profiles, compared to observations, and model skill (not shown). These profiles did not vary with lead time, indicating that they are robust features of the GCM, regardless of MJO strength.

Diabatic-heating profiles from each model were computed by compositing on quartiles of rainfall rate, after first re-gridding the heating and rainfall to a $10^{\circ} \times 10^{\circ}$ horizontal grid to ensure only broad-scale features were cap- a.

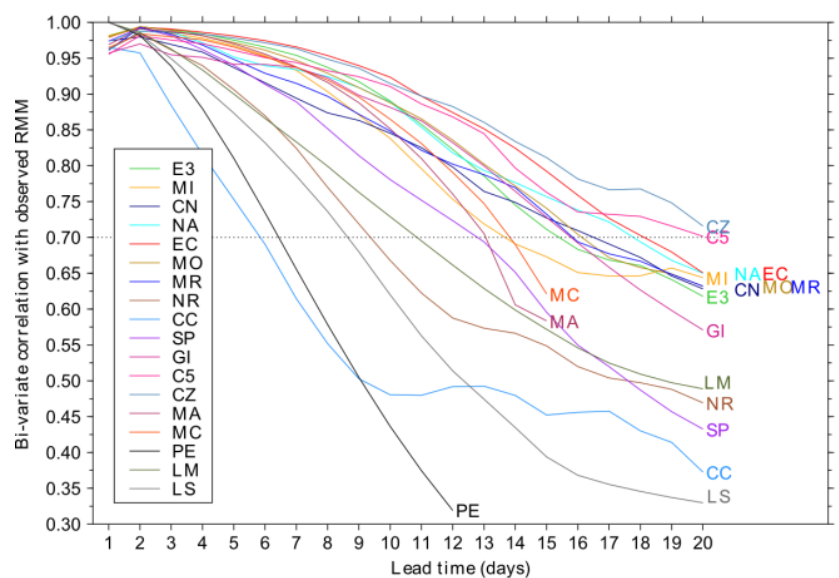

b.

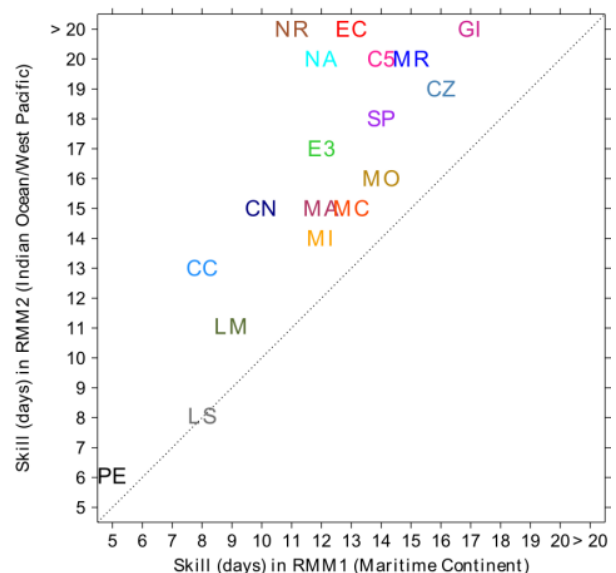

Fig. 5. (a) The bi-variate correlation of model RMM1 and RMM2, with lead time, against observations, for all hindcast dates. (b) Skill in RMM1 and RMM2 for each model, defined as the lead time at which the correlation with observations drops below 0.7. Persistence ("PE") and two linear inverse models ("LS" and "LM") are shown as baseline measures of skill. Models are identified with codes; a complete list is available from the project website. 
a. $\mathrm{Q}_{1}$ from CanCM4

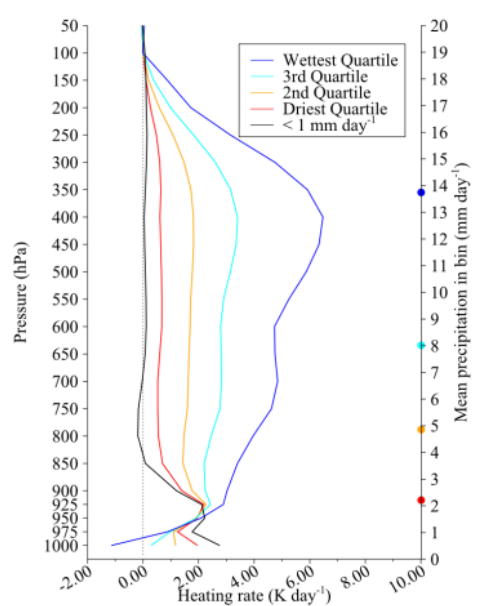

\section{c. $\delta \mathrm{q} / \delta \mathrm{t}$ from CAM5-ZM}

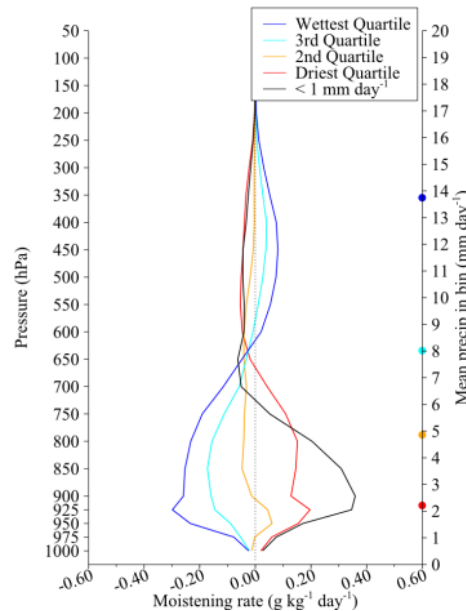

b. $\mathrm{Q}_{1}$ from CAM5-ZM

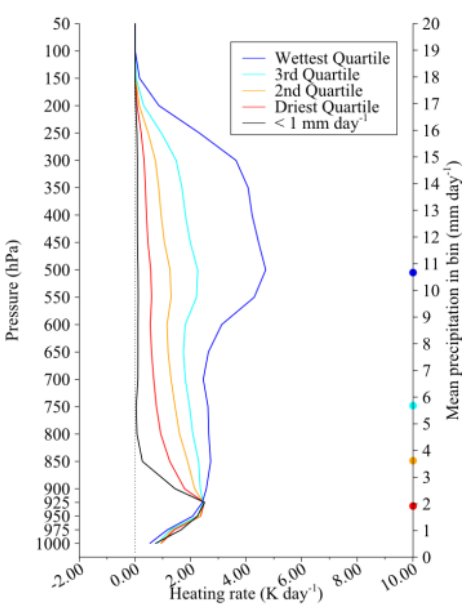

d. $\bar{q} / \overline{\delta t}$ from CAM5-ZM

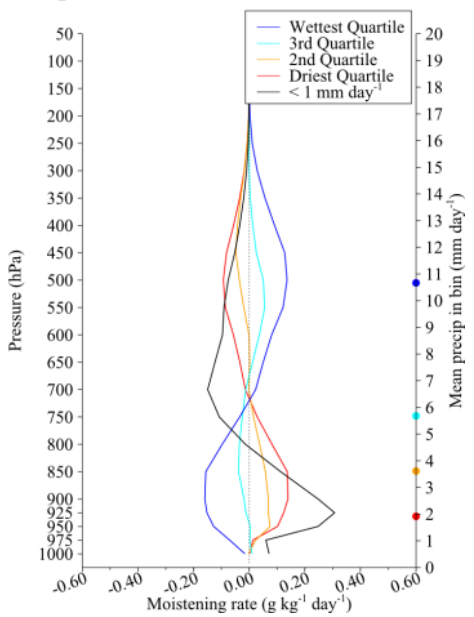

Fig. 6. For 3-hr (a,b) diabatic heating from physics ("Q1") and (c,d) total moistening (dq/dt), composite profiles by rain-rate quartile for $(\mathrm{a}, \mathrm{c})$ CanCM4 and $(\mathrm{b}, \mathrm{d})$ CAM5-ZM). Quartiles are constructed at each grid point, from all rain rates $>1 \mathrm{~mm}$ day $^{-1}$; profiles are averaged over all ocean points in $60^{\circ}-90^{\circ} \mathrm{E}, 10^{\circ} \mathrm{S}-10^{\circ} \mathrm{N}$, using all start dates and lead times. Composite profiles for rain rates $\leq 1 \mathrm{~mm}$ day ${ }^{-1}$ are in black. Symbols on the right-hand axis give the mean rain rate $\left(\mathrm{mm} \mathrm{day}^{-1}\right)$ for each quartile.

tured (Fig. 6). These profiles also largely failed to segregate those models with a high predictive skill from those with lower skill. One poor-performing model, NavGEM ("NR" in Fig. 5; profiles not shown), displayed unrealistically bottom-heavy heating profiles. Another low-skill GCM, CanCM4 ("CC"; Fig. 6a), had a top-heavy profile similar to the high-skill CAM5 (Fig. 6b), as well as a similar evolution of heating profiles with increasing rain rate. A top-heavy heating profile may be a necessary, but not a sufficient condition, for accurate MJO predictions. The composite heating profiles were almost constant with lead time, suggesting that the timestep profiles in Component 2 are not unduly influenced by the short lead time.

A diagnostic based on total moistening (i.e., $\delta \mathrm{q} / \delta \mathrm{t})$, as a function of rain-rate quartile, 
produced a cleaner separation between highand low-skill models. CanCM4 (Fig. 6c) and CAM5 (Fig. 6d) show net moistening at low levels for light rainfall rates (red and black lines), but in the second quartile of precipitation (orange line) CAM5 continues to moisten in the lower troposphere while CanCM4 shows near-zero tendencies. The transition from shallow moistening during the suppressed phase to mid-level and then deep moistening during the active phase was found to be much smoother, and much closer to the YoTC 3-24 hour forecasts, in the high-skill models. The high-skill models all simulated net moistening above the boundary layer in the second quartile, while all of the low-skill models displayed negative or negligible $\delta \mathrm{q} / \delta \mathrm{t}$. The low-skill models showed a too-quick transition, with increasing precipitation, from low-level moistening and upperlevel drying to deep moistening and low-level drying. This suggests a key role for boundarylayer clouds and congestus in the simulation of MJO initiation and propagation. In GCMs, the $\delta \mathrm{q} / \delta \mathrm{t}$ profile is often driven by the counterbalance between dynamics and physics: at high (low) rain rates, the model dynamics moistens (dries) and physics dries (moistens). However, at moderate rain rates $\left(3-6 \mathrm{~mm}\right.$ day $\left.^{-1}\right)$, several high-skill models had mid-tropospheric moistening from both advection and physics, suggesting an accurate transition from suppressed to active MJO conditions may require moistening by both processes.

\section{Summary and Conclusions}

The "Vertical structure and diabatic process of the MJO" global-model evaluation project has established a framework for analyzing biases in model physical parameterizations associated with tropical convection, which affect the simulation and prediction of weather and climate phenomena globally. The three components of the framework provide a robust characterization of MJO activity in a GCM, from the behavior of parameterizations when the model is highly constrained and close to an initial state with an active MJO (Component 2), through to the model's ability to generate and maintain an intra-seasonal oscillation relative to its climatology (Component 1). The third component examines the degradation of the model from the former to the latter, identifying how biases in diabatic heating and moistening profiles may accelerate that degradation.

Analysis of the three components has identified several over-arching conclusions. First, many process-oriented MJO diagnostics derived from previous studies based on one or several models, when applied to the 35 models in this project, fail to distinguish between those models that simulate the MJO well and those that do so poorly, whether in initialized hindcasts or decadal-length simulations. It appears that no single process holds the key to the MJO in these models; rather, there are many processes that are necessary, but not sufficient conditions for a reliable simulation of tropical convection. Second, there is little correlation between a model's skill in predicting the MJO — based only on the two YoTC cases examined - and its ability to generate sub-seasonal variability in a free-running simulation. Several of the bestperforming models in Component 3 (e.g., CAM5 and the U. K. Met Office Unified Model) performed poorly in Component 1, while some of the best models in that component (e.g., the Super-Parameterized CAM and the Goddard Institute for Space Studies ModelE) produced poor hindcasts. Finally, all components have demonstrated that reliable representations of moistening, particularly at low and mid-levels during the transition between suppressed and active phases, may be critical to simulating the MJO (Figs. 2, 4 and 6), perhaps more so than the representation of convective heating.

This project has produced a rich dataset, which is open to the community via: http:// yotc.ucar.edu/mjo/vertical-structure-and-diaba tic-processes-mjo. We have only "scratched the 
surface" of this dataset. Although we have focused on the MJO, the data could be used to examine many other phenomena (e.g., monsoons, equatorial waves, tropical cyclones and tropical-extra-tropical teleconnections); many variables from Components 1 and 3 are available globally, with tendencies available $50^{\circ} \mathrm{N}-$ $50^{\circ} \mathrm{S}$. We hope that further studies will develop and extend these results, to continue to test and refine the physical parameterizations critical to the simulation of tropical sub-seasonal variability.

\section{References}

Andersen, J. A. and Z. Kuang, 2012: Moist static energy budget of MJO-like disturbances in the atmosphere of a zonally symmetric aquaplanet. J. Climate 25, 2782-2804

Benedict, J. J. and D. A. Randall, 2007: Observed characteristics of the MJO relative to maximum rainfall. J. Atmos. Sci. 64, 2332-2354.

Boyle, J. S., S. Klein, G. Zhang, S. Xie, and X. Wei, 2008: Climate model forecast experiments for TOGA COARE. Mon. Wea. Rev. 136, 808-832.

Benedict, J. J., A. H. Sobel, E. D. Maloney, and D. M. Frierson, 2014: Gross moist stability and MJO simulation skill in three full-physics GCMs. J. Atmos. Sci., 71, 3327-3349.

Camargo, S. J., M. C. Wheeler, and A. H. Sobel, 2009: Diagnosis of the MJO modulation of tropical cyclogenesis using an empirical index. J. Atmos. Sci. 66, 3061-3074.

Cassou, C., 2008: Intraseasonal interaction between the Madden-Julian oscillation and the North Atlantic oscillation. Nature 455: 523-527.

CLIVAR Madden-Julian Oscillation Working Group, 2009: MJO simulation diagnostics. J. Climate 22: 3006-3030.

Fu, X. and B. Wang, 2009: Critical roles of the stratiform rainfall in sustaining the Madden-Julian oscillation: GCM experiments. J. Climate 22: 3939-3959.

Gottschalck, J. M. Wheeler, K. Weickmann, F. Vitart, N. Savage, H. Lin, H. Hendon, D. Waliser, K. Sperber, M. Nakagawa, C. Prestrelo, M. Flatau, and W. Higgins, 2010: A framework for assessing operational MaddenJulian oscillation forecasts: A CLIVAR MJO
Working Group project. Bull. Amer. Meteor. Soc. 91, 1247-1258.

Holloway, C. E., S. J. Woolnough, and G. M. S. Lister, 2013: The effects of explicit versus parameterized convection on the $\mathrm{MJO}$ in a large-domain high-resolution tropical case study. Part I: Characterization of large-scale organization and propagation. J. Atmos. Sci. 70, 1342 1369.

Inness, P. M. and J. M. Slingo, 2003: Simulation of the Madden-Julian oscillation in a coupled general circulation model. Part I: Comparison with observations and an atmosphere-only GCM. J. Climate 16, 345-364.

Jiang, X., D. E. Waliser, W. S. Olson, W. K. Tao, T. S. L'Ecuyer, K. F. Li, Y. L. Yung, S. Shige, S. Lang, and Y. N. Takayabu, 2011: Vertical diabatic heating structure of the MJO: Intercomparison between recent reanalyses and TRMM estimates. Mon. Wea. Rev. 139, 3208-3223.

Kim, D., K. Sperber, W. Stern, D. Waliser, I. S. Kang, E. Maloney, W. Wang, K. Weickmann, J. Benedict, M. Khairoutdinov, M. I. Lee, R. Neale, M. Suarez, K. Thayer-Calder, and G. Zhang, 2009: Application of MJO simulation diagnostics to climate models. J. Climate 22: 6413-6436.

Lau, K. M. and L. Peng L, 1987: Origin of lowfrequency (intraseasonal) oscillations in the tropical atmosphere. Part I: basic theory. J. Atmos. Sci. 44: 950-972.

Lavender, S. L. and A. J. Matthews, 2009: Response of the West African monsoon to the MaddenJulian oscillation. J. Climate 22: 4097-4116.

Lawrence, D. M. and P. J. Webster, 2002: The boreal intraseasonal oscillation: Relationship between northward and eastward movement of convection. J. Atmos. Sci. 59: 1593-1606.

Li, C. Y., X. L. Jia, J. Ling, W. Zhou, and C. Zhang, 2009: Sensitivity of MJO simulations to diabatic heating profiles. Clim. Dynam. 32: 167-187.

Ling, J. and C. Zhang, 2011: Structural evolution in heating profiles of the MJO in global reanalyses and TRMM retrievals. J. Climate 24: 825-842.

Lorenz, D. J. and D. L. Hartmann, 2006: The effect of the MJO on the North American monsoon. J. Climate 19: 333-343.

Madden, R. A. and P. R. Julian, 1971: Detection of a 40-50 day oscillation in the zonal wind in the tropical Pacific. J. Atmos. Sci. 28: 702-708.

Madden, R. A. and P. R. Julian, 1994: Observations of the 40-50 day tropical oscillation - a review. Mon. Wea. Rev. 122: 814-837. 
Maloney, E. D., 2009: The moist static energy budget of a composite tropical intraseasonal oscillation in a climate model. J. Climate 22: 711-729.

Pai, D. S., J. Bhate, O. P. Sreejith, and H. R. Hatwar, 2011: Impact of MJO on the intraseasonal variation of summer monsoon rainfall over India. Clim. Dynam. 36: 41-55.

Raymond, D. J., S. S. Sessions, A. H. Sobel, and Z. Fuchs, 2009: The mechanics of gross moist stability. J. Adv. Model. Earth Sys. 1: 1-19.

Stephens, G. L., P. J. Webster, R. H. Johnson, R. Engelen, and T. S. L'Ecuyer, 2004: Observational evidence for the mutual regulation of the tropical hydrological cycle and tropical sea surface temperatures. J. Climate 17: 2213-2224.

Stephens, G. L., T. L'Ecuyer, R. Forbes, A. Gettlemen, J.-C. Golaz, A. Bodas-Salcedo, K. Suzuki, P. Gabriel, and J. Haynes, 2010: Dreary state of precipitation in global models. J. Geophys. Res., 115 (D24), D24,211.

Thayer-Calder, K., and D. A. Randall, 2009: The role of convective moistening in the MaddenJulian oscillation. J. Atmos. Sci. 66: 3297-3312.
Wang, B. and H. Rui, 1990: Dynamics of the coupled moist Kelvin-Rossby wave on an equatorial B-plane. J. Atmos. Sci. 47: 397-413.

Wheeler, M. C. and H. H. Hendon, 2004: An all-season real-time multivariate MJO index: Development of an index for monitoring and prediction. Mon. Wea. Rev. 132: 1917-1932.

Wheeler, M. C., H. H. Hendon, S. Cleland, H. Meinke, and A. Donald, 2009: Impacts of the Madden-Julian oscillation on Australian rainfall and circulation. J. Climate 22: 1482-1498.

Woolnough, S. J., P. N. Blossey, K.-M. Xu, P. Bechtold, J.-P. Chaboureau, T. Hosomi, S. F. Iacobellis, Y. Luo, J. C. Petch, R. Y. Wong, and S. Xie, 2010: Modelling convective processes during the suppressed phase of a Madden-Julian oscillation. Q. J. R. Meteorol. Soc. 136, 333-353.

Xavier, P. K., 2012: Intraseasonal convective moistening in CMIP3 Models, J. Climate, 25, 25692577 . 